\title{
Identification of Plant Compounds Involved in the Microbe-Plant Communication During the Coinoculation of Soybean with Bradyrhizobium elkanii and Delftia sp. strain JD2
}

\author{
Célica Cagide, ${ }^{1}$ Braulio Riviezzi, ${ }^{1}$ Manuel Minteguiaga, ${ }^{1}$ María A. Morel, ${ }^{1,+}$ and \\ Susana Castro-Sowinski ${ }^{1,2}$ \\ ${ }^{1}$ Molecular Microbiology, Institute Clemente Estable, Av. Italia 3318, 11600 Montevideo, Uruguay; and ${ }^{2}$ Biochemistry and \\ Molecular Biology, Faculty of Sciences, Universidad de la República, Igua 4225, 11400 Montevideo, Uruguay
}

Accepted 24 May 2018.

\begin{abstract}
Delftia sp. strain JD2 is a betaproteobacterium characterized as a plant growth-promoting bacterium with a 'helper' function, enhancing the performance of rhizobial inoculant strains during the coinoculation of alfalfa and clover. In this work we analyzed i) the effect of the coinoculation with Bradyrhizobium elkanii and Delftia sp. strain JD2 strains on the performance of soybean plants and ii) the production of a few secondary plant metabolites that would explain the positive effect of coinoculation on the growth and development of soybean plants. The results showed a beneficial effect of coinoculation on soybean growth, nodulation rate, and pulse yield, with the concomitant benefit for the agricultural economy. In addition, based on a metabolomics approach, we demonstrated that a different pattern of plant metabolites is being produced at different stages of plant growth. The new information suggests that the coinoculation of soybean changes the primary and secondary metabolism of the plant, including changes in the metabolic status of main and secondary nodules within the plant. The relevance of producing a different pattern of photosynthetic and photoprotective pigments, flavonoids, organic acids, and carbohydrates are discussed. Finally, we propose that JD2 could be used together with bradyrhizobia to manipulate the chemical composition of plant tissues, promoting the nutritional benefits and health of soybean.
\end{abstract}

Delftia sp. strain JD2 is a $\mathrm{Cr}(\mathrm{VI})$-reducing betaproteobacterium (family Comamonadaceae) that was isolated by our working team many years ago (Morel et al. 2011). JD2 was characterized as a plant growth-promoting bacterium with a 'helper' function, enhancing the performance of rhizobial inoculant strains during the coinoculation of alfalfa and clover

${ }^{\dagger}$ Corresponding author: María A. Morel;

E-mail: mmorel@iibce.edu.uy

Funding: This work was partially supported by PEDECIBA (Program for the Development of Basic Sciences or Programa de Desarrollo de las Ciencias Básicas). The work of Célica Cagide was supported by ANII (the National Agency for Research and Innovation or Agencia Nacional de Investigación e Innovación).

*The $\boldsymbol{e}$-Xtra logo stands for "electronic extra" and indicates that one supplementary figure is published online.

() 2018 The American Phytopathological Society
(Morel et al. 2011, 2015; Ubalde et al. 2012). This bacterium fixes atmospheric nitrogen when growing in $\mathrm{NFb}$ semisolid $\mathrm{N}$-free medium and produces the phytohormone indole-3-acetic acid (IAA) and siderophores (Morel et al. 2011). The analysis of the draft genome from JD2 suggests that IAA is produced by the indole-3-acetamide pathway and that JD2 has the genetic machinery to produce and uptake the siderophore pyoverdine but also has the machinery for the acquisition of Fe-pyochelin and Fe-enterobactin (Morel et al. 2016).

Experiments of coinoculation of alfalfa with Sinorhizobium meliloti U143 (an indigenous strain used as inoculant in Uruguay) (Castro-Sowinski et al. 2002) and JD2 showed an increase of shoot and root dry matter (measured as dry weight) up to 13 and $34 \%$, respectively, in greenhouse conditions, compared with single rhizobial inoculation (Morel et al. 2015). The results support the idea that the coinoculation with JD2 improves agronomic expectations compared with single-rhizobial inoculation, as it has also been shown with the coinoculation of leguminous plants with rhizobial and azospirilla strains (Burdman et al. 1997; Hungria et al. 2013, 2015; Itzigsohn et al. 1993).

The positive effect of Azospirillum (alphaproteobacterium; family Rhodospirillaceae) in the nodulation and nitrogen fixation by rhizobia strains on several pulse and forage legumes has been extensively reported (increase in shoot length and weight, number of root hairs, root diameter, number of root nodules, and the percentage of infected root hairs), thus resulting in increased legume yields (Morel et al. 2012). This plant growth-promoting effect has been explained by the production of plant hormones by Azospirillum spp.; however, the mode of action is currently better explained as an additive and selective effect (Cassán and Díaz-Zorita 2016). Most azospirilla produce auxin, a phytohormone that promotes root development and proliferation, leading to enhanced nutrient uptake and increasing the number of potential niches for beneficial microbial infection (Castillo et al. 2015; Morel and CastroSowinski 2013). Even though both Delftia and Azospirillum spp. strains belong to different classes, they may display similar mechanisms of plant-microbe interaction.

The aims of this work were to analyze the performance of soybean plants subjected to coinoculation with Bradyrhizobium elkanii and Delftia sp. strain JD2 and to contribute to the understanding of the plant response during various stages of plant growth. We conducted gnotobiotic and greenhouse experiments, showing the beneficial effect of coinoculation in plant 
growth, nodulation rate, and pulse yield; in addition, based on a metabolomics approach, we showed that different patterns of plant metabolites are produced at different stages of plant growth.

\section{RESULTS}

Does the coinoculation of soybean with bradyrhizobia and JD2 have an effect on plants growth in gnotobiotic and greenhouse conditions?

The ability of Delftia sp. strain JD2 to improve biomass production and nodulation during the inoculation and coinoculation of alfalfa and clover plants was already shown by Morel et al. (2011; 2015) and Ubalde et al. (2012); thus, in this work, we evaluated the effect of the coinoculation of soybean plants with B. elkanii strains and JD2 in shoot, root, and pod or seed yields and nodulation rate. Results from gnotobiotic plant experiments showed that, in both inoculation and coinoculation treatments, the first nodule appears 7 days after bacterization, but the nodulation rate was 1.2 and 2.0 nodules per plant per day, respectively, suggesting a positive effect of coinoculation on the bradyrhizobial-plant interaction (Fig. 1). The highest number of nodules per plant was achieved 22 days after bacterization, but coinoculated plants ( 23 nodules per plant) reached a higher number of nodules per plant, as compared with bradyrhizobial single-inoculated plants (17 nodules per plant). In addition, when plants grown in greenhouse conditions were collected at the V4 growth stage, only coinoculated plants showed nodules, suggesting an early nodulation induced by JD2. These results suggest that coinoculation with JD2 induces early nodulation and increases the number of nodules per plant.

The ability of Delftia sp. strain JD2 to improve soybean yield during inoculation and coinoculation experiments was assessed as shown in Table 1. In greenhouse conditions at the V4 stage, coinoculation increased shoot dry matter, plant height, and root dry matter up to 18,34 , and $80 \%$, respectively, over bradyrhizobia-inoculated plants (Fig. 2B). Interestingly, single JD2 inoculation increased root dry matter by $43 \%$ compared with a single inoculation with bradyrhizobia, suggesting that JD2 affects soybean root development, at least during the first stages of growth. At R2 stage, results showed an increase of 4 and $14 \%$ in shoot dry matter and plant height but a $10 \%$ reduction in dry root dry matter, suggesting that the most important effect of coinoculation is detected at the first stages of growth. Reinforcing this result, the data obtained from experiments in gnotobiotic conditions also support a positive effect of coinoculation on shoot dry matter and plant height (Table 1). In addition, results obtained by micro Kjeldhal experiments and the determination of ureides showed that the total content of total nitrogen and ureides of coinoculated plants were significantly higher than JD2- or bradyrhizobia-inoculated plants (Table 2), suggesting that coinoculation positively affect the acquisition of nitrogen. Nodules collected from R2 plants were cut in half, showing a reddish interior (Fig. 2D). This observation suggests that they are functionally active nodules.

Probably, the most important effect was observed in the harvest index (HI) (Table 1). Compared with the control treatment, results showed an increase of 35,12 , and $64 \%$ in HI of plants inoculated with JD2, bradyrhizobia, and coinoculated, respectively, suggesting that the coinoculation has an important beneficial effect on the most productive parameter of soybean, the HI.

\section{Does coinoculation alter the profile of plant-produced metabolites?}

We measured some plant performance characteristics, such as chlorophyll and carotenoid content (Table 3; Fig. 2C). A general overview of the table shows that plants from V4 present a much higher content of chlorophylls compared with plants collected at the R2 stage (flowering stage), but the carotenoid content was much higher in plants from the R2 stage. Results also support that coinoculation increased the pigment content of plants (chlorophylls and carotenoids) at the R2 stage, compared with single-inoculated plants. Both the chlorophyll a and chlorophyll b content increased 84 and $66 \%$, respectively, in coinoculated plants compared with bradyrhizobial-inoculated ones (Table 3). The occurrence of a few sets of flavonoids (daidzein, genistein, luteolin, coumestrol), commonly involved in the soybean-bradyrhizobia interaction, was searched on roots and nodules of plants collected at the V4 and R2 stages, grown in greenhouse conditions (Fig. 2C) (the chromatographic profile can be seen in Supplementary Figure S1). These flavonoids were not detected in nodules, and a different pattern of flavonoids (presence/absence) was detected in roots of plants from different treatments.

At the V4 stage, we did not detect the presence of these flavonoids in the root extracts of noninoculated plants (control plants) and bradyrhizobia-inoculated plants showed a minor accumulation of daidzein. However, the accumulation of
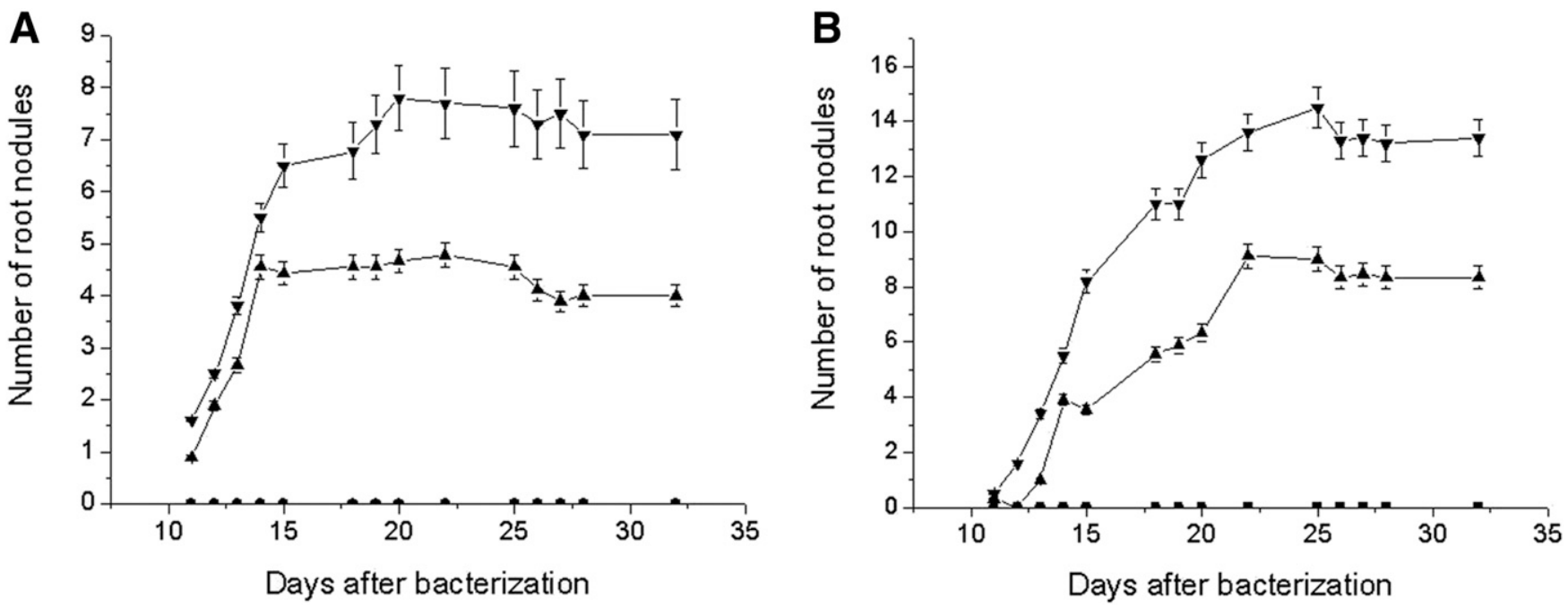

Fig. 1. Data averages for nodules in A, main roots and B, secondary roots. Each point represents the average of all the plants at each date of recording. Upward pointing triangles $(\boldsymbol{\Delta})$ represent plants inoculated with bradyrhizobia, downward pointing triangles ( $\boldsymbol{\nabla})$, coinoculated plants, and black squares $(\boldsymbol{\nabla})$, uninoculated plants. 
daidzein, genistein, luteolin, and coumestrol was observed in the roots of JD2-inoculated and coinoculated plants. The relative integrated area of peaks showed that roots from coinoculated plants have a higher content (tenfold, data not shown) of flavonoids rather than JD2- or bradyrhizobial-inoculated plants, suggesting that, in response to coinoculation, the soybean plants could modify their metabolism for the production of a higher amount of these flavonoids.

Table 1. Effects of different treatments on yield components of soybean ${ }^{\mathrm{a}}$

\begin{tabular}{|c|c|c|c|c|c|}
\hline \multirow[b]{2}{*}{ Stage } & \multirow[b]{2}{*}{ Plant characteristics } & \multicolumn{4}{|c|}{ Treatment } \\
\hline & & Control & $\begin{array}{c}\text { Inoculation } \\
\text { with JD2 }\end{array}$ & $\begin{array}{l}\text { Inoculation with } \\
\text { bradyrhizobia }\end{array}$ & Coinoculation \\
\hline \multicolumn{6}{|c|}{ Greenhouse conditions } \\
\hline \multirow[t]{3}{*}{ V4 stage } & SDM (mg per plant) & $6,750 \pm 91 \mathrm{a}$ & $6,900 \pm 107 a$ & $6,566 \pm 130 a$ & $7,733 \pm 183 a$ \\
\hline & $\mathrm{PH}(\mathrm{cm})$ & $33.5 \pm 4.7 \mathrm{ab}$ & $30.3 \pm 3.6 \mathrm{bc}$ & $26.4 \pm 3.1 \mathrm{c}$ & $35.3 \pm 3.2 \mathrm{a}$ \\
\hline & RDM (mg per plant) & $195.7 \pm 36.9 \mathrm{ab}$ & $206.0 \pm 40.4 \mathrm{ab}$ & $143.3 \pm 44.6 \mathrm{~b}$ & $256.6 \pm 38.8 \mathrm{a}$ \\
\hline \multirow{3}{*}{ R2 stage } & SDM (mg per plant) & $4,294.0 \pm 0.9 \mathrm{~b}$ & $4,586.0 \pm 0.5 b$ & $5,772.0 \pm 1.0 \mathrm{ab}$ & $5,997.0 \pm 0.7 \mathrm{a}$ \\
\hline & $\mathrm{PH}(\mathrm{cm})$ & $38.61 \pm 10.90 \mathrm{~b}$ & $39.84 \pm 9.75 \mathrm{ab}$ & $44.32 \pm 7.18 \mathrm{ab}$ & $50.57 \pm 8.42 \mathrm{a}$ \\
\hline & RDM (mg per plant) & $1,764 \pm 662 a$ & $2,002 \pm 453 \mathrm{a}$ & $1,917 \pm 618 a$ & $1,714 \pm 841 \mathrm{a}$ \\
\hline R8 stage & Harvest index & $0.042 \pm 0.002 \mathrm{c}$ & $0.057 \pm 0.003 \mathrm{~b}$ & $0.047 \pm 0.002 \mathrm{c}$ & $0.069 \pm 0.003 \mathrm{a}$ \\
\hline \multicolumn{6}{|c|}{ Gnotobiotic conditions } \\
\hline \multirow[t]{2}{*}{ V4 stage } & SDM (mg per plant) & $204.2 \pm 36.7 b$ & $183.4 \pm 31.4 b$ & $144.2 \pm 50.7 b$ & $231.5 \pm 40.3 \mathrm{a}$ \\
\hline & $\mathrm{PH}(\mathrm{cm})$ & $38.6 \pm 10.9 \mathrm{~b}$ & $39.8 \pm 9.7 \mathrm{ab}$ & $44.3 \pm 7.2 \mathrm{ab}$ & $50.5 \pm 8.4 \mathrm{a}$ \\
\hline
\end{tabular}

${ }^{a}$ Experiments were performed in greenhouse (harvesting times: V4, R2, and R8) and gnotobiotic conditions. Means followed by different letters are statistically different $(P \leq 0.05)$. SDM $=$ shoot dry matter; RDM $=$ root dry matter; and $\mathrm{PH}=$ plant height.
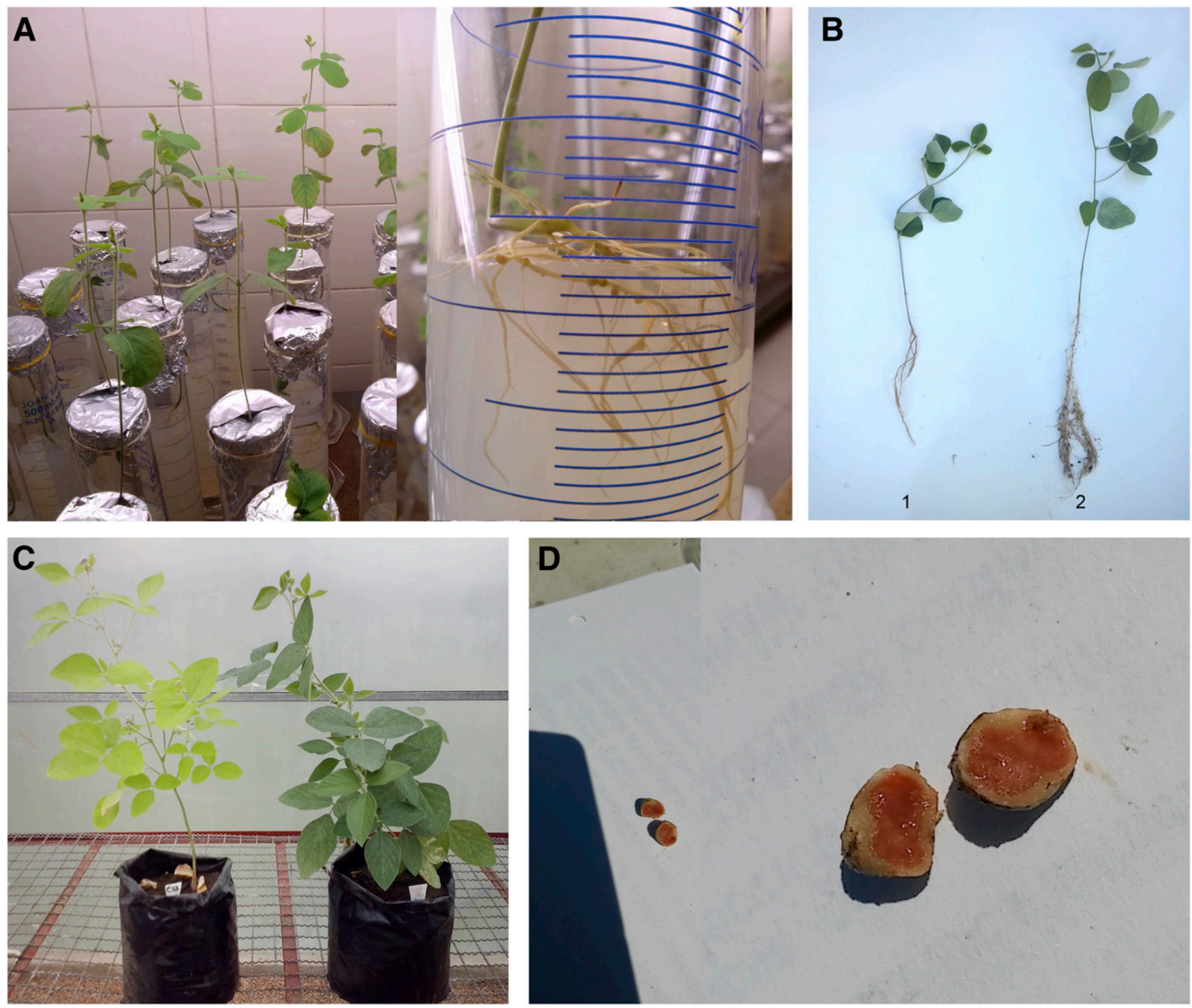

Fig. 2. Gnotobiotic and greenhouse experiments. A, The gnotobiotic system. B, Plants collected at the V4 stage (from greenhouse experiments: 1 is a bradyrhizobiainoculated plant and 2 is a coinoculated plant). C, Bradyrhizobia-inoculated (left) and coinoculated (right) plants, in 5-kg pots, at the R2 stage. D, Reddish interior from nodules from the main root of plants grown in greenhouse conditions and collected at the R2 stage (the right side shows a zoom of the nodules). 
The biochemical analysis of roots collected at the R2 stage showed a different composition of flavonoids compared with roots from plants collected at V4 stage. At the R2 stage, daidzein, genistein, and coumestrol were detected in noninoculated control plants but at low levels; no flavonoids were detected in JD2inoculated plants, suggesting that they would have already been degraded or excreted by the plant; an increased level of daidzein was detected in bradyrhizobia-inoculated plants, accompanied by the detection of low amounts of genistein, luteolin, and coumestrol; and in roots from the coinoculated plants, daidzein, genistein, luteolin, and coumestrol were detected but at lower levels than those detected in plants collected during stage V4 (when nodulation was already established in plants from greenhouse experiments). The relative integrated area of peaks showed a similar abundance of flavonoids in bradyrhizobia-inoculated and

Table 2. Total nitrogen and ureides content of plants collected at R2 stage (greenhouse experiments) $^{\mathrm{a}}$

\begin{tabular}{lcc}
\hline Treatment & $\begin{array}{c}\text { Total nitrogen } \\
(\mathbf{m g} / \mathbf{g} \text { of SDM) }\end{array}$ & $\begin{array}{c}\text { Ureides } \\
(\mathbf{m g} / \mathbf{g} \text { of SDM) }\end{array}$ \\
\hline Control & $7.938 \pm 1.203 \mathrm{c}$ & $0.190 \pm 0.157 \mathrm{~b}$ \\
Inoculation with JD2 & $12.721 \pm 0.722 \mathrm{bc}$ & $0.301 \pm 0.122 \mathrm{~b}$ \\
Inoculation with bradyrhizobia & $13.904 \pm 1.379 \mathrm{~b}$ & $0.359 \pm 0.139 \mathrm{~b}$ \\
Coinoculation & $20.632 \pm 4.021 \mathrm{a}$ & $0.942 \pm 0.011 \mathrm{a}$ \\
\hline
\end{tabular}

${ }^{a}$ Means followed by different letters are statistically different $(P \leq 0.10)$. $\mathrm{SDM}=$ shoot dry matter. coinoculated plants (daidzein and coumestrol as the major flavonoids, two- and tenfold higher than genistein and luteolin, respectively).

Results of analysis by gas chromatography coupled to mass spectrometry (GC-MS) are shown in Tables 4, 5, and 6. Many organic acids (including fatty acids and amino acids) and carbohydrates were detected in all treatments. A general overview of results suggests that roots from coinoculated plants contain a few compounds that were not found on control or single-inoculated plants (bradyrhizobia or JD2inoculated plants). In other words, a small set of compounds were only found in coinoculated plants and could contribute to the understanding of how coinoculation may contribute to a better plant performance. At growth stage V4, the fatty acids caproic and pentadecanoic, the amino acids glutamine and aspartate, and the sugars fructose and galactose were detected only in coinoculated root plants; meanwhile, oleic, linolenic, arachidonic, and monopalmitin acids, hydroxybutyric acid, glycerol, proline, and glutamine were found only in roots collected at growth stage R2.

The presence of low molecular-weight compounds in nodules (main and secondary ones) collected at R2 stage is shown in Table 5. Interestingly, the composition of metabolites in main and secondary nodules from the same treatment showed a different pattern of compounds, no matter what treatment we consider, bradyrhizobia-inoculated or coinoculated plants. In addition, we detected a differential pattern of compounds between nodules from different treatments. However, a few compounds, such

Table 3. Chlorophylls and carotenoid content in soybean plants, at V4 or R2 stage, grown in greenhouse conditions ${ }^{\mathrm{a}}$

\begin{tabular}{|c|c|c|c|c|c|}
\hline Treatment & Total chlorophyll & Chlorophyll a & Chlorophyll b & b/a ratio & Carotenoids \\
\hline \multicolumn{6}{|l|}{ V4 stage } \\
\hline Control & $5.267 \mathrm{a}$ & $2.009 \mathrm{a}$ & $3.258 \mathrm{~b}$ & $1.622 \mathrm{~b}$ & $0.999 \mathrm{~b}$ \\
\hline Inoculation with JD2 & $5.712 \mathrm{a}$ & $1.893 \mathrm{a}$ & $3.819 \mathrm{~b}$ & $2.018 \mathrm{a}$ & $1.056 \mathrm{~b}$ \\
\hline Inoculation with bradyrhizobia & $6.483 \mathrm{a}$ & $2.334 \mathrm{a}$ & $4.149 \mathrm{a}$ & $1.778 \mathrm{~b}$ & $1.240 \mathrm{a}$ \\
\hline Coinoculation & $4.956 \mathrm{~b}$ & $1.869 \mathrm{a}$ & $3.087 \mathrm{~b}$ & $1.651 \mathrm{~b}$ & $0.991 \mathrm{~b}$ \\
\hline \multicolumn{6}{|l|}{ R2 stage } \\
\hline Control & $0.409 \mathrm{~b}$ & $0.305 \mathrm{c}$ & $0.104 \mathrm{c}$ & $0.341 \mathrm{~b}$ & $14.30 \mathrm{~b}$ \\
\hline Inoculation with JD2 & $0.477 \mathrm{~b}$ & $0.336 \mathrm{c}$ & $0.141 \mathrm{~b}$ & $0.419 \mathrm{a}$ & $16.30 \mathrm{~b}$ \\
\hline Inoculation with bradyrhizobia & $0.556 \mathrm{~b}$ & $0.418 \mathrm{~b}$ & $0.138 \mathrm{~b}$ & $0.330 \mathrm{~b}$ & $20.60 \mathrm{a}$ \\
\hline Coinoculation & $1.418 \mathrm{a}$ & $1.189 \mathrm{a}$ & $0.229 \mathrm{a}$ & $0.193 \mathrm{c}$ & $30.50 \mathrm{a}$ \\
\hline
\end{tabular}

a Values are expressed in milligrams of pigment per gram of fresh leaf. Different letters indicate significant differences between treatments $(P \leq 0.05)$.

Table 4. Chemical composition of roots collected at V4 growth stage during greenhouse experiments ${ }^{\mathrm{a}}$

\begin{tabular}{|c|c|c|c|c|}
\hline Chemical family & All treatments ${ }^{\mathbf{a}}$ & Inoculation with bradyrhizobia & Inoculation with JD2 & Coinoculation \\
\hline \multirow[t]{3}{*}{ Fatty acids } & Palmitic acid & $\ldots$ & $\ldots$ & Caproic acid \\
\hline & Valeric acid & $\ldots$ & $\ldots$ & Pentadecanoic acid \\
\hline & Stearic acid & $\ldots$ & $\ldots$ & $\ldots$ \\
\hline \multirow[t]{4}{*}{ Carboxylic acid and derivatives } & Succinic acid & $\ldots$ & Butyric acid & $\ldots$ \\
\hline & Malic acid & $\ldots$ & Malonic acid & Malonic acid \\
\hline & Propanoic acid & $\ldots$ & Gluconic acid & Gluconic acid \\
\hline & Threonic acid & $\ldots$ & $\ldots$ & $\ldots$ \\
\hline \multirow{5}{*}{$\begin{array}{l}\text { Amides, amines, amino acids, and other } \\
\text { N-compounds }\end{array}$} & Butanamine & Proline & Proline & Glutamine \\
\hline & Alanine & Urea & Urea & Aspartic acid \\
\hline & Valine & $\ldots$ & Tyrosine & $\ldots$ \\
\hline & Serine & $\ldots$ & $\ldots$ & $\ldots$ \\
\hline & Threonine & $\ldots$ & & \\
\hline \multirow[t]{6}{*}{ Carbohydrates } & Arabinose & Xylose & Ribose & Ribose \\
\hline & myo-Inositol & $\ldots$ & $\ldots$ & Fructose \\
\hline & Mannose & $\ldots$ & $\ldots$ & Galactose \\
\hline & Glucose & $\ldots$ & $\ldots$ & $\ldots$ \\
\hline & Xylitol & $\ldots$ & $\ldots$ & $\ldots$ \\
\hline & Sucrose & $\ldots$ & $\ldots$ & $\ldots$ \\
\hline \multirow[t]{2}{*}{ Phytosterols } & $\ldots$ & $\ldots$ & Stigmasterol & $\ldots$ \\
\hline & $\ldots$ & $\ldots$ & Sitosterol & $\ldots$ \\
\hline
\end{tabular}

${ }^{a}$ Compounds detected in all treatments, including nonbacterized controls. Compounds exclusively found in a specific treatment are indicated in the corresponding column. Experiments were done at least three times, showing similar trends, but results shown are from one of three independent experiments. 
as hydroxybutyric and malic acids were found in both main and secondary nodules in all tested conditions.

\section{DISCUSSION}

The use of plant growth-promoting microorganisms in agricultural systems improves the growth and development of plants, including the yield of many commercial crops and seed stocks. Among others, there are many reports on the beneficial effect of the combined use (coinoculation) of bacteria of the genus Azospirillum and rhizobia on a variety of plants, due to their ability to promote the growth of plants through one or both the production of phytohormones (IAA and cytokinins) and the ability to fix atmospheric nitrogen (Morel et al. 2012). The coinoculation may also change the composition of root-exuded molecules such as flavonoids, as described by Morel et al. (2015) and Volpin et al. (1996).
In this work, we worked under the hypothesis that proposes that the coinoculation of soybean seeds with Delftia sp. strain JD2 and B. elkani strains improves the nodulation and productivity of plants compared with single inoculation and that the production of some secondary metabolites would explain the positive effect of coinoculation on the growth and development of soybean plants. As a first step, we faced bacterial antagonist tests. The results showed that they (JD2, U1301, and U130) are not antagonist to each other (data not shown).

Experiments performed in gnotobiotic and greenhouse conditions support that the coinoculation of soybean with bradyrhizobia and Delftia sp. strain JD2 induce early nodulation, a higher number of nodules per plant, and improved soybean yield, including the accumulation of total nitrogen, ureides, and the HI. A study done by the United States Department of Agriculture Economic Research Service in 2011 showed a large increase in grain yield of $23.4 \mathrm{~kg}$ per hectare per year between

Table 5. Chemical composition of roots collected at R2 growth stage during greenhouse experiments ${ }^{\mathrm{a}}$

\begin{tabular}{|c|c|c|c|c|}
\hline Chemical family & All treatments & Inoculation with bradyrhizobia & Inoculation with JD2 & Coinoculation \\
\hline Fatty acids & $\begin{array}{l}\text { Stearic acid } \\
\text { Palmitic acid } \\
\ldots \\
\ldots\end{array}$ & $\begin{array}{l}\cdots \\
\cdots \\
\cdots \\
\cdots\end{array}$ & $\begin{array}{l}\text { Linoleic acid } \\
\ldots \\
\ldots \\
\ldots\end{array}$ & $\begin{array}{l}\text { Oleic acid } \\
\text { Linolenic acid } \\
\text { Arachidonic acid } \\
\text { Monopalmitin }\end{array}$ \\
\hline Carboxylic acid and derivatives & $\begin{array}{l}\text { Propanoic acid } \\
\text { Malic acid } \\
\ldots \\
\ldots \\
\ldots \\
\ldots \\
\ldots\end{array}$ & $\begin{array}{l}\text { Benzoic acid } \\
\ldots \\
\ldots \\
\ldots \\
\ldots \\
\ldots \\
\ldots\end{array}$ & $\begin{array}{l}\text { Butanoic acid } \\
\text { Gluconic acid } \\
\text { Glucuronic acid } \\
\text { Malonic acid } \\
\text { Maleic acid } \\
\text { Lactic acid } \\
\text { Cinnamic acid }\end{array}$ & $\begin{array}{l}\text { Benzoic acid } \\
\text { Gluconic acid } \\
\text { Hydroxybutyric } \\
\ldots \\
\ldots \\
\ldots \\
\ldots\end{array}$ \\
\hline $\begin{array}{l}\text { Amides, amines, amino acids and others } \\
\text { N-compounds }\end{array}$ & $\begin{array}{l}\text { Proline } \\
\text { Serine } \\
\text { Aspartic acid } \\
\text { Lysine } \\
\text { Butanamine }\end{array}$ & $\begin{array}{l}\text { Alanine } \\
\text { Glycine } \\
\text { Valine } \\
\ldots \\
\text { Urea }\end{array}$ & $\begin{array}{l}\cdots \\
\cdots \\
\cdots \\
\cdots \\
\cdots\end{array}$ & $\begin{array}{l}\text { Alanine } \\
\text { Glycine } \\
\text { Glutamine } \\
\text { Proline } \\
\text { Urea }\end{array}$ \\
\hline Carbohydrates & $\begin{array}{l}\text { Ribose } \\
\text { Inositol } \\
\text { Galactose } \\
\text { Glucose } \\
\text { Arabinose } \\
\text { Fructose }\end{array}$ & $\begin{array}{l}\ldots \\
\ldots \\
\ldots \\
\ldots \\
\ldots \\
\ldots\end{array}$ & $\begin{array}{l}\text { Glycerol } \\
\text { Maltose } \\
\text { Mannose } \\
\text { Xylose } \\
\text { Xylitol } \\
\text { Melibiose }\end{array}$ & $\begin{array}{l}\text { Dulcitol } \\
\text { Glycerol } \\
\ldots \\
\ldots \\
\text { Xylitol } \\
\ldots\end{array}$ \\
\hline Phytosterols & $\begin{array}{l}\text { Stigmasterol } \\
\text { Sitosterol }\end{array}$ & $\begin{array}{l}\text { Campesterol } \\
\ldots\end{array}$ & $\begin{array}{l}\ldots \\
\ldots\end{array}$ & $\begin{array}{l}\text { Campesterol } \\
\ldots\end{array}$ \\
\hline
\end{tabular}

${ }^{a}$ Compounds listed in the All-treatments column were detected in all treatments, including nonbacterized controls. Compounds exclusively found in a specific treatment are listed in the corresponding column. Experiments were done at least three times, showing similar trends, but results are from one of three independent experiments.

Table 6. Chemical composition of nodules collected at R2 growth stage, during greenhouse experiments ${ }^{\mathrm{a}}$

\begin{tabular}{|c|c|c|c|c|}
\hline \multirow[b]{2}{*}{ Chemical family } & \multicolumn{2}{|c|}{ Nodules on the main root } & \multicolumn{2}{|c|}{ Nodules on the secondary roots } \\
\hline & Inoculation with bradyrhizobia & Coinoculation & Inoculation with bradyrhizobia & Coinoculation \\
\hline Fatty acids & $\begin{array}{l}\text { Tetracosenoic acid } \\
\ldots\end{array}$ & $\begin{array}{l}\ldots \\
\cdots\end{array}$ & $\begin{array}{l}\text { Propanodioic acid } \\
\ldots\end{array}$ & $\begin{array}{l}\text { Palmitic acid } \\
\text { Propanoic acid }\end{array}$ \\
\hline Carboxylic acid and derivatives & $\begin{array}{l}\text { Acetic acid } \\
\text { Keto-d-gluconic acid } \\
\text { Hexanoic acid } \\
\text { Pentonic acid } \\
\text { Altronic acid } \\
\text { Ribonic acid }\end{array}$ & $\begin{array}{l}\text { Malonic acid } \\
\ldots \\
\ldots \\
\ldots \\
\ldots \\
\ldots\end{array}$ & $\begin{array}{l}\text { Palmitic acid } \\
\ldots \\
\ldots \\
\ldots \\
\ldots \\
\ldots\end{array}$ & $\begin{array}{l}\text { Keto d-gluconic acid } \\
\text { Glucuronic acid } \\
\ldots \\
\ldots \\
\ldots \\
\ldots\end{array}$ \\
\hline $\begin{array}{l}\text { Amides, amines, amino acids and other } \\
\text { N-compounds }\end{array}$ & the & $\begin{array}{l}\text { Glutamine } \\
\ldots\end{array}$ & $\begin{array}{l}\text { Urea } \\
\ldots\end{array}$ & Proline \\
\hline Carbohydrates & $\begin{array}{l}\text { Galactose } \\
\ldots \\
\ldots \\
\ldots\end{array}$ & $\begin{array}{l}\text { Melibiose } \\
\text { Mannose } \\
\ldots \\
\ldots\end{array}$ & $\begin{array}{l}\text { Melobiose } \\
\text { Ribose } \\
\text { Lactose } \\
\ldots\end{array}$ & $\begin{array}{l}\text { Galactofuranose } \\
\text { Turanose } \\
\text { Glucose } \\
\text { Maltose }\end{array}$ \\
\hline
\end{tabular}

\footnotetext{
${ }^{a}$ Compounds exclusively found in a specific treatment are listed in the corresponding column. Experiments were done at least three times, showing similar trends, but results are from one of three independent experiments.
} 
1924 and 2011 in the United States but this high yield would not meet the demands predicted by 2050 (Ray et al. 2013). Thus, the data obtained in greenhouse experiments show that coinoculation with JD2 increases soybean grain yield, overcoming agronomic expectations, and probably increasing agricultural commodities, helping buyers and sellers to trade in commodity and, ultimately, benefiting the farmers.

Understanding the role that the molecules have during the plant-microbe interaction might help to propose new strategies to increase agronomical practices. Thus, we searched for a set of compounds commonly found in leaves (photosynthetic and photoprotective pigments), roots and nodules (flavonoids, organic acids, sugars). We sought to answer the following question: Does coinoculation change the profile of plant metabolites? If so, may these compounds explain the beneficial effect of coinoculation on soybean?

Chlorophyll a is the main pigment involved in photoelectron transport, the process that provides the energy for photosynthesis (Ripullone et al. 2003). In addition to chlorophyll a, the antenna complex contains other pigments (chlorophyll b, carotenoids, and xanthophylls) that absorb light from different wavelengths, which can also be used for photosynthesis. Chlorophyll $b$ is found in the external antennas of photosystems (Busheva et al. 1991), and the ratio chlorophyll b/a thus allows the estimation of the relative amount of external antennas per reaction center. Carotenoids are involved in the assembling of photosystems and act as light-harvesting antenna complexes for photosynthesis and photoprotection but also have a function in the regulation of plant growth and development (Nisar et al. 2015). The information gathered during this work (higher number of external antennas for each reaction center and increased content of carotenoids in coinoculated plants compared with bradyrhizobial-inoculated ones) suggests that coinoculation may help to increase the nutrient status of plants and to cope with the damaging effects of light. The increase in the content of photosynthetic and photoprotective pigments by the inoculation with Azospirillum brasilense of wheat seedlings (Bashan et al. 2006) and Arabidopsis thaliana (Cohen et al. 2015) was already reported, reinforcing the hypothesis that some bacteria may influence the content of pigments produced by plants.

Flavonoids are plant-specific compounds that activate the genes involved in the production of the nodulation factor by the rhizobia. These chemical factors trigger the formation of nodules in the roots of the leguminous plants, and daidzein (the most abundant flavonoid in soybean), genistein, and coumestrol are key signal compounds in the establishment of the symbiosis between bradyrhizobia and soybean (Antunes et al. 2006; Juge et al. 2012). We showed that roots from coinoculated plants have tenfold higher content of flavonoids compared with JD2or bradyrhizobia-inoculated plants (at the V4 growth stage), suggesting that, in response to coinoculation, the soybean plants could modify their metabolism for the production of a higher amount of these flavonoids. The results suggest that coinoculated plants would show a better performance for the development of nodules, mainly at the V4 plant-growth stage. Likely, as shown above, once the nodule is established (R2 growth stage), coinoculated plants slow the production of flavonoid (or raise their degradation) and change their metabolism to produce other molecules with much relevance in the anabolic metabolism. Probably, when nodules and the nitrogen-fixation process are already established the amount of flavonoids within the root is kept at a steady state and they no longer influence the symbiotic processes.

Among the compounds found by GC-MS, the amino acid glutamine is clearly involved in nitrogen fixation. The fixed nitrogen is transformed to ammonium into the bacteroid, then assimilated into glutamine (and aspartate) and, finally, through the purine pathway, and a series of oxidation and enzymatic steps is converted into ureides. The ureides are transported, via the xylem, to the rest of the plant. It has been suggested that the amount of glutamine (and aspartate) must be balanced in the nodule and this balancing is essential for improving nodule function and nitrogen assimilation (Carter and Tegeder 2016). In addition, the amino acid proline, found in roots from R2 plants, may act as an osmolyte, but proline is also known for stabilizing subcellular structures such cell membranes, scavenging free radicals, and buffering the redox potential of cells (Hayat et al. 2012). Thus, this result could mean that nodules from coinoculated plants are better prepared for nitrogen fixation than are nodules from bradyrhizobia-inoculated plants.

Among the different treatments, we did not find differences in the pattern of fatty acids produced, although the presence of the short-chain fatty acids caproic acid (C6:0) on roots from coinoculated plants must be highlighted. This fatty acid has been linked to membrane fluidity and may indicate that the plant cell membrane is now more fluid and prone to bacterial colonization, as previously suggested by Brechenmacher et al. (2010). The same result was obtained in previous studies performed on alfalfa root exudates, i.e., the presence of caproic acid in 15-day exudates of plants coinoculated with JD2 and Sinorhizobium meliloti U143 (Morel et al. 2015).

The different pattern of metabolites found in main and secondary nodules from bradyrhizobia-inoculated and coinoculated plants suggests that both kinds of nodules have either a different function, react differently, or both to the coinoculation. Once again, glutamine shows up, now as a compound only found in the main nodules of coinoculated plants, suggesting that the metabolism of amino acids is still very active in nodules from coinoculated plants at R2.

Other compounds, such as hydroxybutyric and malic acids were found in main and secondary nodules in all tested conditions. The presence of hydroxybutyrate in soybean nodules is a widely reported feature in bradyhrizobia. The $\beta$-hydroxybutyric acid is commonly present in roots and nodules of soybean and is accumulated as polyhydroxybutyrate in the bacteroids and used as carbon source when the supply of carbohydrates from the plant is limited (Wong and Evans 1971). Some authors propose that the degradation of this compound in nodules maintains the oxygen demand of the bacteroids during darkness, preserving the activity of the nodule and the biological nitrogen fixation until the stage of grain development (Bergersen et al. 1991).

Malic acid is the main carbon source transported to the bacteriods (Udvardi and Poole 2013). It is possible that the malic acid present in nodules and roots of the inoculated and coinoculated soybean comes from the Krebs cycle. The Krebs cycle, as a central metabolic pathway in rhizobia, provides reduction equivalents (NADH and FADH2) for the production of energy and metabolic intermediates for the production of amino acids and other biosynthetic pathways. In summary, the detection of intermediary metabolites of the Krebs cycle in roots of coinoculated plants as well as of metabolites related to the assimilation of nitrogen suggests that these plants are actively producing reducing equivalents and energy, which could be used for biomass production, including grains.

In summary, the new information suggests that coinoculation with B. elkanii and Delftia sp. strain JD2 strains induces a higher yield and harvest rate of soybean compared with the bradyrhizobia single inoculation, with a concomitant benefit for the agricultural economy. The results suggest that the coinoculation of soybean changes the primary and secondary metabolism of the plant. Consequently, JD2 could be used together with bradyrhizobia to manipulate the chemical 
composition of plant tissues, promoting the nutritional benefits and health of soybean. Interestingly, an overview of results from GC-MS carried out on nodules showed that main and secondary nodules have a different metabolic status within the plant and that the coinoculation may change the flux (or rate) of metabolic pathways, anabolic or catabolic ones, yielding different chemical products with different benefits. Based on these inferences, future work will focus on the study of the differential expression of proteins (by shotgun of proteins) and genes (by RNA-seq) among the main and secondary nodules from bradyrhizobia-inoculated and coinoculated plants.

\section{MATERIALS AND METHODS}

\section{Bacterial strains.}

The bacterial strains used in the present study were Delftia sp. strain JD2 (Morel et al. 2011) and the microsymbionts of soybean (Glycine max) Bradyrhizobium elkanii U1301 and U1302 from the commercial formulation LIKUIQ produced by Lage \& Cia S.A. (initial microbial concentration of $5 \times 10^{9}$ $\mathrm{CFU} \mathrm{m} \mathrm{m}^{-1}$ ). JD2 cells were grown in tryptone-yeast medium ( $5 \mathrm{~g}$ of tryptone, $3 \mathrm{~g}$ of yeast extract, and $0.09 \mathrm{~g}$ of anhydrous $\mathrm{CaCl}_{2}$ per liter) at $30^{\circ} \mathrm{C}$ and $200 \mathrm{rpm}$. Growth was monitored by measuring optical density at $620 \mathrm{~nm}$. The antagonism was determined by the disk agar diffusion test, by means of the dual confrontation between JD2 and one bradyrhizobium at a time, as described by Hewitt and Vincent (1989).

\section{Gnotobiotic plant experiments.}

Surface-sterilized soybean seeds (GE 590ci) (15 min in 20\% $\mathrm{NaClO}$, rinsed with and soaked in sterilized water) were pregerminated in soft agar at $30^{\circ} \mathrm{C}$ in dark conditions. Then, pregerminated seeds were sown in 500-ml test tubes (one seed per tube [Fig. 2A]) containing $450 \mathrm{ml}$ of sterile nitrogen-free mineral solution (Somasegaran and Hoben 1985) and $0.8 \%$ agar (Sigma; low nitrogen-content agar) and were inoculated with either $100 \mu \mathrm{l}$ of bacterial suspension of JD2 $\left(10^{7} \mathrm{CFU} / \mathrm{ml}\right)$,

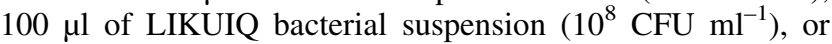
both, per seed. All plants were incubated for 32 days at $26^{\circ} \mathrm{C}$, under a photoperiod of $16 \mathrm{~h}$ of light and $8 \mathrm{~h}$ of dark. The light was supplied through Gro-lux tubes (Sylvania). Nodules were counted daily and the main and secondary root nodules were recorded. After 32 days of growth, shoot and root dry matter (SDM and RDM, respectively) were measured after drying at $60^{\circ} \mathrm{C}$ until constant weight.

\section{Greenhouse experiments.}

Soybean seeds (GE 590ci) were surface-sterilized and were transferred to 5-kg pots (for harvesting of plants at V4 or R2 growth stages) or 8-kg pots (for harvesting of plants at physiological maturity, growth stage R8) (10 pots per treatment; three seeds per pot) filled with nonsterile soil, sand, and vermiculite $(2: 2: 1)$. A completely randomized block experiment was designed. Seeds were inoculated with one or both B. elkanii and JD2 ( $10^{7}$ and $10^{6}$ CFU per seed, respectively). Ten days later, two plants per pot were thinned out, and the plants that showed uniformity of growth appearance were used for further experiments. Plants were grown at $30^{\circ} \mathrm{C}(16 \mathrm{~h}$ light and $8 \mathrm{~h}$ dark), using Gro-lux lamps (Sylvania), and were irrigated every 3 days (to soil water capacity) with water, 10-fold diluted Jensen medium (Vincent 1970), or calcium hyperphosphate solution ( $1 \mathrm{~g}$ per liter), alternately. As control treatment uninoculated, nitrogen-free plants were used. Soybean plants were cut $1 \mathrm{~cm}$ above the pot soil at V4 and R2 growth stages (30 and 80 days after inoculation, approximately). SDM and RDM were measured after drying at $60^{\circ} \mathrm{C}$ until constant weight. When plants reached the R8 stage (approximately 180 days after sowing), grain yield was determined. The number, weight, and length of pods and the number and weight of grains were determined. The HI was also determined as the ratio between the grain yield and the total aerial biomass of the crop (total aerial part including grains), according to Koester et al. (2014). The determination of total nitrogen in plants was done by micro Kjeldhal, using the service provided by Ecotech. The content of ureides in soybean plants was analyzed as described by Vogels and Van der Drift (1970).

\section{Chlorophyll and carotenoid content.}

Fresh leaves $(250 \mathrm{mg})$ of plants grown under greenhouse conditions were collected up to stages V4 and R2, were macerated in $12.5 \mathrm{ml}$ of $80 \%$ acetone, on an ice bed (low temperature) and in dark conditions, and were centrifuged at $10,400 \times g$ for $3 \mathrm{~min}$ at $4^{\circ} \mathrm{C}$. The content of chlorophyll $\mathrm{a}$ and $\mathrm{b}$ and total carotenoids were determined at 663, 647, and $470 \mathrm{~nm}$, respectively (Pompelli et al. 2013). The contents of pigments were determined using the Arnon equations (Arnon 1949), but based on Pompelli et al. (2013) modifications.

\section{Preparation of samples for chromatographic experiments.}

Leaves, roots, and nodules from plants collected in stages V4 and R2 were lyophilized and, then, ground with liquid nitrogen. The extraction of methanol (flavonoids), methanol/chloroform/ water (12:5:3) (amino acids and carbohydrates) and acetone/ ethanol (1:1) soluble compounds was performed as described by Sérandour et al. (2008) and Juge et al. (2012). Compounds were solubilized in $50 \mu \mathrm{l}$ of acetonitrile and derivatized by silylation, using $50 \mu \mathrm{l}$ of $\mathrm{N}$-methyl-N-(trimethylsilyl)trifluoroacetamide (Sigma-Aldrich), as described by Sérandour et al. (2008) and Morel et al. (2015).

\section{Identification of low molecular weight metabolites.}

Low molecular-weight metabolites, including flavonoids, amino acids, and carbohydrates were identified by GC-MS using GCMS-QP 2010 Ultra equipment (Shimadzu) with an auto-injector (AOC-20i; Shimadzu). For analyses, a deactivated guard column ( $5 \mathrm{~m}$ length $\times 0.25 \mathrm{~mm}$ ID; Restek) and an analytical capillary column HP-5MS (30 m length $\times 0.25 \mathrm{~mm}$ ID $\times 0.25 \mu \mathrm{m}$ film thickness; Agilent, J \& W Columns) were employed. The carrier gas was helium at a flow rate of $1.0 \mathrm{ml}$ per minute. The oven temperature program was as follows: kept to $80^{\circ} \mathrm{C}$ for $2 \mathrm{~min}$, then increased to $290^{\circ} \mathrm{C}\left(8^{\circ} \mathrm{C} \mathrm{min}^{-1}\right)$, maintained at $290^{\circ} \mathrm{C}$ for $3 \mathrm{~min}$, then increased to $310^{\circ} \mathrm{C}\left(20^{\circ} \mathrm{C}\right.$ $\min ^{-1}$ ), and finally, maintained at $310^{\circ} \mathrm{C}$ for $10 \mathrm{~min}$. The temperature of the injector and detector was $300^{\circ} \mathrm{C}$ during all analyses. Sample aliquots of $1 \mu \mathrm{l}$ (prepared as described above) were injected in splitless mode and were analyzed (total ion current) using the GC-MS Solutions software from Shimadzu, ionization energy, $70 \mathrm{eV}$ and mass scan range, 50 to $850 \mathrm{~m} / \mathrm{z}$.

The identification of the metabolites was performed by comparison (at least 95\% match) with standard mass spectra stored in commercially available libraries (NIST and Wiley). To confirm the chemical identity of the compounds, linear retention indices (LRIs) were calculated by injection of a solution of n-alkanes (C7 to C36; Supelco). In all cases, differences between theoretical and experimental calculated LRI values were smaller than 10 units, confirming the MS identification.

\section{Statistics.}

All experiments were performed at least three times and the data were subjected to one-way analysis of variance (ANOVA), using PAST software version 1.56, with post hoc pair-wise comparison based on Tukey's honestly significant difference test when the ANOVA showed significant inequality of means. 
Statistical significance was determined at $P<0.05$. Homogeneous groups were designated by superscript letters.

\section{ACKNOWLEDGMENTS}

The authors thank Lage \& Cia S.A. for providing the commercial bradyrhizobial inoculant. S. Castro-Sowinski and M. A. Morel are members of the National Research System (SNI, Sistema Nacional de Investigadores) of ANII-Uruguay.

\section{LITERATURE CITED}

Antunes, P. M., Rajcan, I., and Goss, M. J. 2006. Specific flavonoids as interconnecting signals in the tripartite symbiosis formed by arbuscular mycorrhizal fungi, Bradyrhizobium japonicum (Kirchner) Jordan and soybean (Glycine max (L.) Merr.). Soil Biol. Biochem. 38:533-543.

Arnon, D. I. 1949. Copper enzymes in isolated chloroplasts. Polyphenoloxidase in Beta vulgaris. Plant Physiol. 24:1-15.

Bashan, Y., Bustillos, J. J., Leyva, L. A., Hernandez, J.-P., and Bacilio, M. 2006. Increase in auxiliary photoprotective photosynthetic pigments in wheat seedlings induced by Azospirillum brasilense. Biol. Fertil. Soils 42:279-285.

Bergersen, F. J., Peoples, M. B., and Turner, G. L. 1991. A role for poly$\beta$-hydroxybutyrate in bacteroids of soybean root nodules. Proc. R. Soc. Lond., B 245:59-64.

Brechenmacher, L., Lei, Z., Libault, M., Findley, S., Sugawara, M., Sadowsky, M. J., Sumner, L. W., and Stacey, G. 2010. Soybean metabolites regulated in root hairs in response to the symbiotic bacterium Bradyrhizobium japonicum. Plant Physiol. 153:1808-1822.

Burdman, S., Kigel, J., and Okon, Y. 1997. Effects of Azospirillum brasilense on nodulation and growth of common bean (Phaseolus vulgaris L.). Soil Biol. Biochem. 29:923-929.

Busheva, M., Garab, G., Liker, E., Tóth, Z., Szèll, M., and Nagy, F. 1991. Diurnal fluctuations in the content and functional properties of the light harvesting chlorophyll $\mathrm{a} / \mathrm{b}$ complex in thylakoid membranes: Correlation with the diurnal rhythm of the mRNA level. Plant Physiol. 95:997-1003.

Carter, A. M., and Tegeder, M. 2016. Increasing nitrogen fixation and seed development in soybean requires complex adjustments of nodule nitrogen metabolism and partitioning processes. Curr. Biol. 26:2044-2051.

Cassán, F., and Díaz-Zorita, M. 2016. The contribution of the use of Azospirillum sp. in sustainable agriculture: Learnings from the laboratory to the field. Pages 293-321 in: Microbial Models: From Environmental to Industrial Sustainability. Springer, Singapore.

Castillo, P., Molina, R., Andrade, A., Vigliocco, A., Alemano, S., and Cassán, F. D. 2015. Phytohormones and other plant growth regulators produced by PGPR: The Genus Azospirillum. Pages 115-138 in: Handbook for Azospirillum. Springer, Cham, Switzerland.

Castro-Sowinski, S., Carrera, I., Catalán, A. I., Coll, J., and Martinez-Drets, G. 2002. Occurrence, diversity and effectiveness of mid-acid tolerant alfalfa nodulating rhizobia in Uruguay. Symbiosis 32:105-118.

Cohen, A. C., Bottini, R., Pontin, M., Berli, F. J., Moreno, D., Boccanlandro, H., Travaglia, C. N., and Piccoli, P. N. 2015. Azospirillum brasilense ameliorates the response of Arabidopsis thaliana to drought mainly via enhancement of ABA levels. Physiol. Plant. 153:79-90.

Hayat, S., Hayat, Q., Alyemeni, M. N., Wani, A. S., Pichtel, J., and Ahmad, A. 2012. Role of proline under changing environments. Plant Signal. Behav. 7:1456-1466.

Hewitt, W., and Vincent, S. 1989. Theory and application of microbiological assay. Academic Press, San Diego.

Hungria, M., Nogueira, M. A., and Araujo, R. S. 2013. Co-inoculation of soybeans and common beans with rhizobia and azospirilla: Strategies to improve sustainability. Biol. Fertil. Soils 49:791-801.

Hungria, M., Nogueira, M. A., and Araujo, R. S. 2015. Soybean seed coinoculation with Bradyrhizobium spp. and Azospirillum brasilense: A new biotechnological tool to improve yield and sustainability. Am. J. Plant Sci. 6:811-817.
Itzigsohn, R., Kapulnik, Y., Okon, Y., and Dovrat, A. 1993. Physiological and morphological aspects of interactions between Rhizobium meliloti and alfalfa (Medicago sativa) in association with Azospirillum brasilense. Can. J. Microbiol. 39:610-615.

Juge, C., Prévost, D., Bertrand, A., Bipfubusa, M., and Chalifour, F.P. 2012. Growth and biochemical responses of soybean to double and triple microbial associations with Bradyrhizobium, Azospirillum and arbuscular mycorrhizae. Appl. Soil Ecol. 61:147-157.

Koester, R. P., Skoneczka, J. A., Cary, T. R., Diers, B. W., and Ainsworth, E. A. 2014. Historical gains in soybean (Glycine max Merr.) seed yield are driven by linear increases in light interception, energy conversion, and partitioning efficiencies. J. Exp. Bot. 65:3311-3321.

Morel, M. A., Braña, V., and Castro-Sowinski, S. 2012. Legume crops, importance and use of bacterial inoculation to increase production. Pages 217-240 in: Crop Plant. InTechOpen. Published online

Morel, M. A., Cagide, C., Minteguiaga, M. A., Dardanelli, M. S., and Castro-Sowinski, S. 2015. The pattern of secreted molecules during the co-inoculation of alfalfa plants with Sinorhizobium meliloti and Delftia sp. strain JD2: An interaction that improves plant yield. Mol. PlantMicrobe Interact. 28:134-142.

Morel, M. A., and Castro-Sowinski, S. 2013. The complex molecular signaling network in microbe-plant interaction. Pages 169-199 in: Plant Microbe Symbiosis: Fundamentals and Advances. Springer, New Delhi.

Morel, M. A., Iriarte, A., Jara, E., Musto, H., and Castro-Sowinski, S. 2016. Revealing the biotechnological potential of Delftia sp. JD2 by a genomic approach. AIMS Bioeng. 3:156-175.

Morel, M. A., Ubalde, M. C., Braña, V., and Castro-Sowinski, S. 2011. Delftia sp. JD2: A potential $\mathrm{Cr}(\mathrm{VI})$-reducing agent with plant growthpromoting activity. Arch. Microbiol. 193:63-68.

Nisar, N., Li, L., Lu, S., Khin, N. C., and Pogson, B. J. 2015. Carotenoid metabolism in plants. Mol. Plant 8:68-82.

Pompelli, M. F., França, S. C., Tigre, R. C., De Oliveira, M. T., Sacilot, M., and Pereira, E. C. 2013. Spectrophotometric determinations of chloroplastidic pigments in acetone, ethanol and dimethylsulphoxide Rev. Bras. Bioscienc. 11:52-58.

Ray, D. K., Mueller, N. D., West, P. C., and Foley, J. A. 2013. Yield trends are insufficient to double global crop production by 2050. PLoS One 8: e66428.

Ripullone, F., Grassi, G., Lauteri, M., and Borghetti, M. 2003. Photosynthesis-nitrogen relationships: Interpretation of different patterns between Pseudotsuga menziesii and Populus $\times$ euroamericana in a mini-stand experiment. Tree Physiol. 23:137-144.

Sérandour, J., Reynaud, S., Willison, J., Patouraux, J., Gaude, T., Ravanel, P., Lempérière, G., and Raveton, M. 2008. Ubiquitous water-soluble molecules in aquatic plant exudates determine specific insect attraction. PLoS One 3:e3350.

Somasegaran, P., and Hoben, H. J. 1985. Methods in Legume-Rhizobium Technology. United States Agency for International Development and The University of Hawaii, Paia, HI, U.S.A.

Ubalde, M. C., Braña, V., Sueiro, F., Morel, M. A., Martínez-Rosales, C., Márquez, C., and Castro-Sowinski, S. 2012. The versatility of Delftia sp. isolates as tools for bioremediation and biofertilization technologies. Curr. Microbiol. 64:597-603.

Udvardi, M., and Poole, P. S. 2013. Transport and metabolism in legumerhizobia symbioses. Annu. Rev. Plant Biol. 64:781-805.

Vincent, J. M. 1970. A manual for the practical study of root-nodule bacteria. Handbook No. 15. Blackwell Scientific Publications, Oxford.

Vogels, G. D., and Van der Drift, C. 1970. Differential analyses of glyoxylate derivatives. Anal. Biochem. 33:143-157.

Volpin, H., Burdman, S., Castro-Sowinski, S., Kapulnik, Y., and Okon, Y. 1996. Inoculation with Azospirillum increased exudation of rhizobial nod gene inducers by alfalfa roots. Mol. Plant-Microbe Interact. 9: 388-394.

Wong, P. P., and Evans, H. J. 1971. Poly- $\beta$-hydroxybutyrate utilization by soybean (Glycine max Merr.) nodules and assessment of its role in maintenance of nitrogenase activity. Plant Physiol. 47:750-755. 